\title{
Factors affecting recognition of cancer risks of nuclear workers
}

\author{
George W Kneale, Alice M Stewart
}

\begin{abstract}
Objectives-To discover whether direct estimates of the risks of cancer for nuclear workers agree with indirect estimates based on survivors of the atomic bomb; whether relations between age at exposure and risk of cancer are the same for workers and survivors, and whether dosimetry standards are sufficiently uniform to allow pooling of data from differ-
\end{abstract} ent nuclear industrial sites.

Method-Data from five nuclear sites in the United States were included in a cohort analysis that as well as controlling for all the usual factors also allowed for possible effects of three cancer modulating factors (exposure age, cancer latency, and year of exposure). This analysis was first applied to three distinct cohorts, and then to two sets of pooled data.

Results-From each study cohort there was evidence of a risk of cancer related to dose, and evidence that the extra radiogenic cancers had the same overall histological manifestations as naturally occurring cancers and were largely the result of exposures after 50 years of age causing deaths after 70 years. There were, however, significant differences between the five sets of risk estimates.

Conclusions-Although the risks of cancer in nuclear workers were appreciably higher than estimates based on the cancer experiences of survivors of the atomic bomb, some uncertainties remained as there were non-uniform standards of dosimetry in the nuclear sites. The differences between nuclear workers and survivors of the atomic bomb were largely the result of relations between age at exposure and risk of cancer being totally different for workers and survivors and, in the occupational data, there were no signs of the special risks of leukaemia found in atomic bomb data and other

Department of Public Health and

Epidemiology,

University of

Birmingham,

Edgbaston,

Birmingham

GW Kneale

A M Stewart

Correspondence to:

Dr A M Stewart,

Department of Public

Deaarthent of Public

Health and Epidemiology,

University of Birmingham,

Edgbaston,

Accepted 27 April 1995 studies of effects of high doses.

(Occup Environ Med 1995;52:515-523)

Keywords: cancer; radiation; workers

Since 1977, when Mancuso and his associates first found evidence of a risk of cancer for nuclear workers at Hanford, ${ }^{1}$ there have been both confirmations and rebuttals of this occupational hazard. ${ }^{2}$ On one side of this Hanford controversy we have Kneale et al, whose find- ings are indicative of a risk that has left exposures in people over 50 causing most of the extra cancer deaths after 70 years. ${ }^{3-5}$ On the opposite side we have Gilbert et al who have used standardised mortality ratio analyses to show that Hanford workers have low rates of cancer mortality, and cohort analyses to show that risk estimates based on atomic bomb data are directly applicable to nuclear workers. ${ }^{6-9}$ According to atomic bomb data the risk of cancer from repeated exposure to small doses of radiation should be too small to show in the Hanford data, and exposures in people over 50 should be less dangerous than earlier exposures. ${ }^{10}$ Therefore, when recently confronted with "evidence of an increase in the excess relative risk with increasing age" Gilbert and her associates immediately suspected biased dosimetry. ${ }^{11}$ They did, however, admit that "additional analyses addressing the modifying effects of factors such as age at exposure, time since exposure, calendar period of exposure, age at risk, birth cohort, and calendar year of risk would be desirable".

The Hanford controversy is important as the main alternatives to atomic bomb data are occupational data, and biased dosimetry is important as the International Agency for Research on Cancer (IARC) is currently basing risk estimates for "carcinogenic effects of protracted low-dose exposures to radiation" on pooled data from the United States, Canada, and the United Kingdom. ${ }^{12}$ Therefore, included in the present report are data from five nuclear sites, together with the results of pooled and unpooled data in models of relative risk the variables of which included lag period, age at exposure, and year of exposure.

\section{Methods}

DATA

From the Hanford Environmental Health Foundation and the Oak Ridge Associated Universities the records of 85642 badge monitored workers from five nuclear sites (Hanford, and four locations in or near Oak Ridge-that is, X10 (the Oak Ridge National Laboratory), Y12, K25, and Fernald; table 1) were obtained. These data were then divided into three study cohorts (table 2). In the first were all the workers who had ever been at Hanford (cohort $\mathrm{H}$, with 35868 workers and 1907 cancer cases). In the second were all the remaining workers who had ever been at X10 (cohort X, with 22239 workers and 430 cancer cases), and in the third were all the residual workers (cohort Y, with 27535 workers and 
639 cancer cases). As well as these cohorts, two further sets of pooled data were obtained by first combining all the non-Hanford data (cohort XY with 49774 workers and 1069 cancer cases), and then adding the Hanford cohort (cohort HXY with 85642 workers and 2976 cancers).

Table 1 Derivation of the study cohorts of badge monitored workers from two sets of computerised data

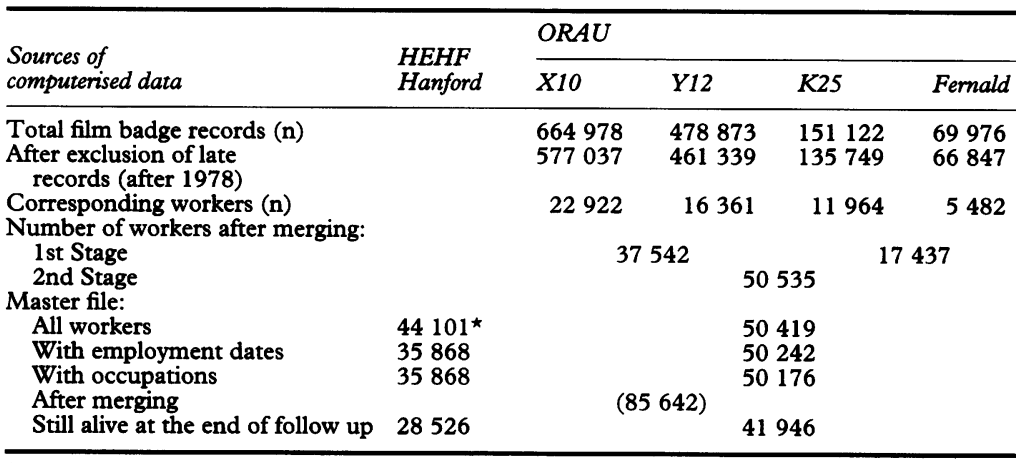

*Includes 8233 workers who were never issued with radiation badges. HEHF = Hanford Environmental Health Foundation; ORAU = Oak Ridge Associated Universities.

Table 2 Further specifications of the five study cohorts

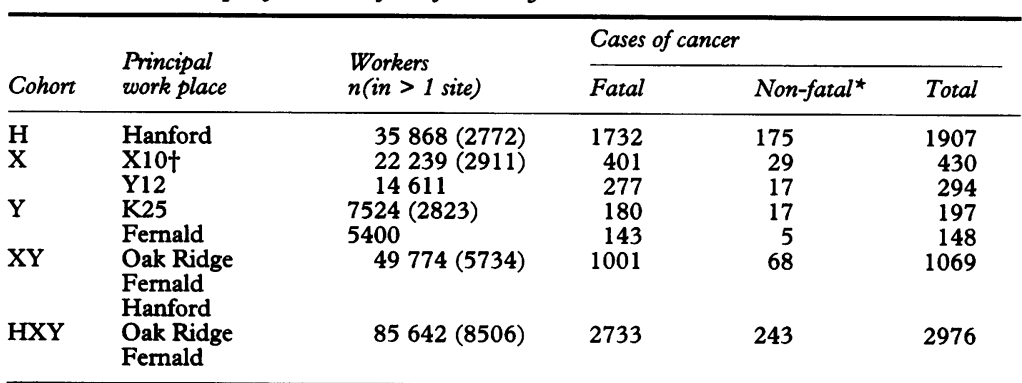

*Non-fatal cancers with other stated causes of death; tprobably synonymous with Oak Ridge National Laboratory (ORNL)

Starting dates: Hanford 1944; X10 1943; K25 1945; Fernald 1952; Y12 1954

Final dates: (1) for death ascertainment: Hanford 1986; elsewhere 1984 (2) for recorded doses: 1978 all workers.

Table 3 Essential controlling factors for the cohort analysis

\begin{tabular}{|c|c|c|c|}
\hline Factor & Levels & Details & \\
\hline $\begin{array}{l}\text { Sex } \\
\text { Race } \\
\text { Year of birth } \\
\text { Year of hire } \\
\text { Site: }\end{array}$ & $\begin{array}{r}2 \\
2 \\
20 \\
13 \\
17\end{array}$ & $\begin{array}{l}\text { M; F } \\
\text { White; other } \\
\text { 5-year intervals: } 1870 \text { to } 1964 \\
\text { 2-year intervals: } 1944 \text { to } 1978 \\
\text { X10 only } \\
\text { Y12 } \\
\text { X10 + Y12 } \\
\text { K25 only } \\
\text { K25 + X10 } \\
\text { K25 + Y12 } \\
\text { K25 + Y12 + X10 } \\
\text { Fernald only } \\
\text { Fernald + X10 } \\
\text { Fernald + Y12 } \\
\text { Fernald + Y12 + X10 } \\
\text { Fernald + K25 + F10 } \\
\text { Fernald + K25 + X10 } \\
\text { Fernald + K25 + Y12 + F10 } \\
\text { Fernald + K25 + Y12 + X10 } \\
\text { Hanford only } \\
\text { Hanford and elsewhere }\end{array}$ & \\
\hline Potential year of death ${ }^{\star}$ & 43 & 1-year intervals: 1944 to 1986 & \\
\hline Socioeconomic status ${ }^{\star}$ & 6 & $\begin{array}{l}\text { Hanford cohort } \\
\text { Professional } \\
\text { Managerial } \\
\text { Clerical } \\
\text { Craftsmen } \\
\text { Other blue collar } \\
\text { Not specified }\end{array}$ & $\begin{array}{l}\text { Other cohorts } \\
\text { Monthly salary } \\
\text { Contract salary } \\
\text { Other salary } \\
\text { Weekly wage } \\
\text { Hourly wage } \\
\text { No record }\end{array}$ \\
\hline State at discharge ${ }^{\star}$ & 17 & $\begin{array}{l}\text { Died at work: yes/no } \\
\text { If still alive: } \\
\text { Still working after age } 60 \text { years } \\
\text { State at discharge recorded } \\
\text { Employment }>3 \text { y } \\
\text { Period after employment }>3 \text { y }\end{array}$ & $\begin{array}{l}\text { Yes/no } \\
\text { yes/no } \\
\text { yes/no } \\
\text { yes/no }\end{array}$ \\
\hline
\end{tabular}

^Separate assessment for each calendar year.
For Hanford workers there were occupational data but no pay status records, and for other workers there were pay status records but no occupational data. Therefore, for the six socioeconomic levels in table 3 there are different criteria for Hanford and elsewhere. Several of the essential controlling factors in this table were needed to cope with obvious differences between the five sites. For example, at Hanford there were deaths to the end of 1986; elsewhere there were only deaths to the end of 1984, and births before 1900 were much commoner at Hanford (5\%) than elsewhere $(1.5 \%)$. The final year of dose recording was always the same (1978) but there were different starting dates, ranging from 1943 for X10 to 1954 for Y12. Until 1960 the average annual dose was higher for X10 than elsewhere, but thereafter the lead was taken by Hanford and, for the whole period, the average annual dose rate was higher for this cohort $(2.9 \mathrm{mSv})$ than for $\mathrm{X}(1.55 \mathrm{mSv})$ or $\mathrm{Y}$ $(0.70 \mathrm{mSv})$ (table 4). Finally, although deaths from cancers of digestive organs were twice as common as deaths from genitourinary cancers, among the 243 cases that were contributory causes of non-cancer deaths (so called non-fatal cancers) there were almost as many genitourinary as lung cancers (table 5).

\section{STATISTICAL ANALYSIS}

In many respects the method of statistical analysis was identical to the one recommended by Breslow and Day for cohort studies (appendix). ${ }^{13}$ But over and above the procedures required for identification of suitable models of relative risk there were additional procedures to cope with the computer storage problems created by a need to observe the effects of adding extra variables to a simple model of relative risk (table 6). As in the 1993 analysis of Hanford data ${ }^{5}$ the main variable in the model was expressed as a doubling dose $(\beta)$, and for the exponent of dose response $(\varepsilon)$ the expected value (assuming linearity) was $1 \cdot 0$. One of three parameters for "cancer modulating factors" was common to each model, namely, cancer latency (lag period) $(\delta)$, and only the simplest of four models (model I) had no allowance for age at exposure $(a)$. The fifth parameter (which was also the fourth dose-weighting factor) was year of exposure $(\gamma)$. This factor was common to two of the three remaining models (III and IV), but only with model IV was there a full compliment of five parameters.

This statistical model was developed from the one used in the first cohort analysis of Hanford data by Kneale, Mancuso, and Stewart in $1981 .^{3}$ The earlier analysis recognised the fact that there are sound radiobiological reasons for assuming that, at low dose levels, each component of the total dose acts separately and can be combined additively. Also, in common with earlier analyses of atomic bomb data, it was recognised that the effect of a given dose may depend on cancer modulating factors such as sex, the age when exposed, and the interval between exposure and death (or cancer latency). According to these assumptions the overall effect of a 
Table 4 Three distinct cohorts: average workforce (W) and average annual radiation doses $(R)$ for seven consecutive periods

\begin{tabular}{|c|c|c|c|c|c|c|}
\hline \multirow[b]{2}{*}{ Period } & \multicolumn{2}{|c|}{ Cohort $H$} & \multicolumn{2}{|c|}{ Cohort X } & \multicolumn{2}{|c|}{ Cohort $Y$} \\
\hline & $W$ & $R m S v$ & $W$ & $R m S v$ & $W$ & $R m S z$ \\
\hline $\begin{array}{l}\text { Pre } 1950 \\
1950-54 \\
1955-59 \\
1960-64 \\
1965-69 \\
1970-74 \\
1975-78 \\
1943-78\end{array}$ & $\begin{array}{l}5379 \\
7773 \\
8769 \\
8361 \\
8379 \\
7127 \\
9146 \\
7740\end{array}$ & $\begin{array}{l}1.02 \\
1.50 \\
2.40 \\
4.47 \\
4.86 \\
3.28 \\
2.37 \\
2.92\end{array}$ & $\begin{array}{l}2116 \\
3635 \\
4464 \\
4975 \\
5875 \\
5546 \\
7319 \\
4620\end{array}$ & $\begin{array}{l}1.87 \\
2.13 \\
3.53 \\
1.94 \\
1.20 \\
0.69 \\
0.39 \\
1.55\end{array}$ & $\begin{array}{r}182 \\
1150 \\
2720 \\
5597 \\
6166 \\
6629 \\
10926 \\
5696\end{array}$ & $\begin{array}{l}1.19 \\
0.95 \\
1.81 \\
1.01 \\
0.82 \\
0.66 \\
0.31 \\
0.70\end{array}$ \\
\hline
\end{tabular}

Table 5 Primary sites of three series of fatal (F) and non-fatal (NF) cancers

\begin{tabular}{|c|c|c|c|c|c|c|c|c|}
\hline \multirow[b]{2}{*}{$I C D-8$} & \multicolumn{2}{|c|}{ Cohort $H$} & \multicolumn{2}{|c|}{ Cohort X } & \multicolumn{2}{|c|}{ Cohort Y } & \multicolumn{2}{|l|}{ Total } \\
\hline & $F$ & $N F$ & $F$ & $N F$ & $F$ & $N F$ & $F$ & $N F$ \\
\hline $\begin{array}{l}\text { 140-149 Mouth and pharynx } \\
150-159 \text { Gastrointestinal } \\
160-163 \text { Respiratory } \\
\text { 170-174 Bone and connective } \\
\text { tissue }\end{array}$ & $\begin{array}{r}41 \\
461 \\
532 \\
106\end{array}$ & $\begin{array}{r}3 \\
41 \\
46 \\
3\end{array}$ & $\begin{array}{r}12 \\
98 \\
109 \\
26\end{array}$ & $\begin{array}{r}- \\
6 \\
-\end{array}$ & $\begin{array}{r}7 \\
142 \\
225 \\
23\end{array}$ & $\begin{array}{r}3 \\
4 \\
10 \\
-\end{array}$ & $\begin{array}{r}60 \\
701 \\
866 \\
155\end{array}$ & $\begin{array}{r}6 \\
51 \\
63 \\
3\end{array}$ \\
\hline $\begin{array}{l}\text { 180-189 Genitourinary } \\
\text { 190-194 Brain and endocrine } \\
\text { 195-199 Non-specific } \\
\text { 200-203 Lymphomas } \\
\text { 204-209 Leukaemias } \\
\text { Totals }\end{array}$ & $\begin{array}{r}223 \\
59 \\
128 \\
112 \\
70 \\
1732\end{array}$ & $\begin{array}{r}49 \\
4 \\
11 \\
7 \\
11 \\
175\end{array}$ & $\begin{array}{r}59 \\
11 \\
32 \\
30 \\
24 \\
401\end{array}$ & $\begin{array}{r}6 \\
2 \\
2 \\
4 \\
2 \\
29\end{array}$ & $\begin{array}{r}72 \\
27 \\
36 \\
44 \\
24 \\
600\end{array}$ & $\begin{array}{r}6 \\
3 \\
2 \\
6 \\
5 \\
39\end{array}$ & $\begin{array}{r}354 \\
97 \\
196 \\
186 \\
118 \\
2733\end{array}$ & $\begin{array}{r}61 \\
9 \\
15 \\
17 \\
18 \\
243\end{array}$ \\
\hline
\end{tabular}

ICD-8 $=$ international classification of diseases 8 th revision.

series of annual doses can be given by a weighted sum of these doses, where the weight for each dose depends on the relevant cancer modulating factors.

When there is only one exposure with a large effect and plenty of data (as with atomic bomb data) the dose-weights can be estimated by the general linear model (GLIM) statistical package. But for workers in the nuclear industry there may be as many as 30 annual doses, and for the total workforce there may be over a thousand combinations of two modulating factors (age at exposure and latency). Furthermore, the estimated number of radiogenic cancers is likely to be small $(<100)$, so direct application of GLIM would probably lead to overfitting and large fluctuations in the dose-weighting estimates. The statistical model can be simplified so that the weighting for a given annual dose is the product of the separate weights for the relevant modulating factors. As mentioned above, however, each worker can have up to 30 annual doses, so a weighting curve for age at exposure might need as many as 30 separate numbers to describe it, and thus leave the problem of overfitting unresolved.

The final formulation of the 1981 risk

Table 6 Parameters of four models of relative risk

\begin{tabular}{lllllll}
\hline & \multicolumn{3}{l}{ Main parameters } & & \multicolumn{3}{l}{ Extra parameters } \\
\cline { 2 - 3 } \cline { 5 - 6 } Model & $\beta$ & $\varepsilon$ & & $\delta^{l}$ & $a^{l}$ & $\gamma^{l}$ \\
\hline I & E & E & & E & DV & DV \\
II & E & E & & E & E & DV \\
III & E & DV & & E & E & E \\
IV & E & E & & E & E & E \\
\hline
\end{tabular}

$\mathrm{E}=$ an estimated value by maximum likelihood; $\mathrm{DV}=$ default value; $\beta=$ doubling dose in $\mathrm{mSv} ; \varepsilon=$ exponent of dosevalue; $\beta=$ doubling dose in $\mathrm{mSv} ; \varepsilon=$ exponent of dose-
response; $\delta=$ minimum cancer latency or lag period; $a=$ miniresponse; $\delta=$ minimum cancer latency or exposire; $\gamma=$ latest exposure yearitical values mum age exposure; $\gamma=$ latest exposure year; $1=$ critical values
marking the boundaries of "risk set windows" (fig 2 and marking

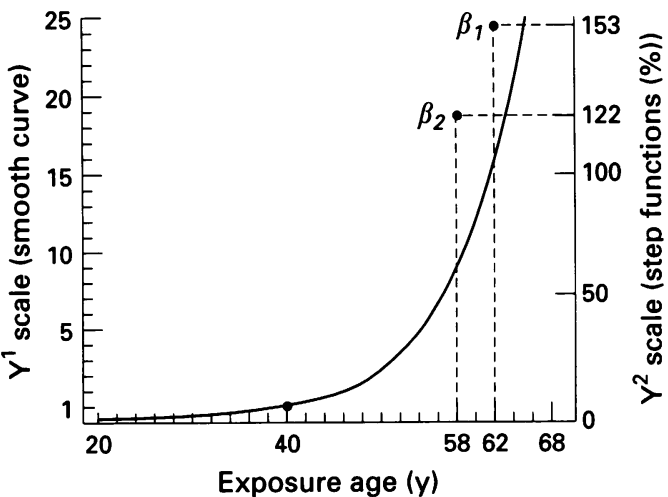

Figure 1 Age related increase in sensitivity to the effects of radiation in induction of cancer according to several models.

model had each weighting curve for the separate modulating factors dependent on one parameter. For example, in the 1981 analysis of Hanford data, the effect of age at exposure was estimated by a smooth exponential curve running through 1.0 at age 40 ; increasing by a fixed percentage for every subsequent year, and decreasing by the same fixed percentage for every previous year (fig 1). Likewise, the effect of latency assumed that for each worker the latency was distributed as a $\chi^{2}$ with 4 degrees of freedom (after division by the mean latency).

In the 1993 analysis of Hanford data (and in the present analysis) instead of smooth curves (of some assumed functional form with one variable parameter for each modulating factor) the weighting curves for the cancer modulating factors were assumed to be step functions, with 1.0 for all values above a critical level, and zero for all lower values. It will be seen that if this method is used for latency weighting (with the critical value for latency corresponding to the lag period) the result is formally identical to the lagged dose model used by Gilbert et $a l^{9}$ and Wing et al. ${ }^{14}$ As well as step functions for the weighting of two modulating factors (exposure age and latency), the analyses used by Wing et $a l^{14}$ recognised a third modulating factor, namely, calendar year of exposure. This additional factor allowed for suspected variations in the effect per unit dose due to faulty dosimetry or changes in monitoring programmes between 1944 and $1978 .{ }^{15}$ Finally, although one of the cancer modulating factors in the atomic bomb data analyses was sex, this was ignored in the three analyses as most of workers in the nuclear industry were men.

With step functions as weighting curves for three modulating factors it was possible to have a "window" for each worker, to mark the limits of any "cancer effective doses" defined as any annual doses that had 1.0 as the value for all three step functions (fig 2 and $\beta_{1}$ and $\beta_{2}$ in fig 1 ). Once the critical values for age at exposure $(a)$, latency $(\delta)$, and year of exposure $(\gamma)$, were known, each "window dose" $(Z)$ could be calculated from the vector of annual doses, and then the relative risk in the year corresponding to the end of the latency could also be calculated by the formula $R=1+$ 


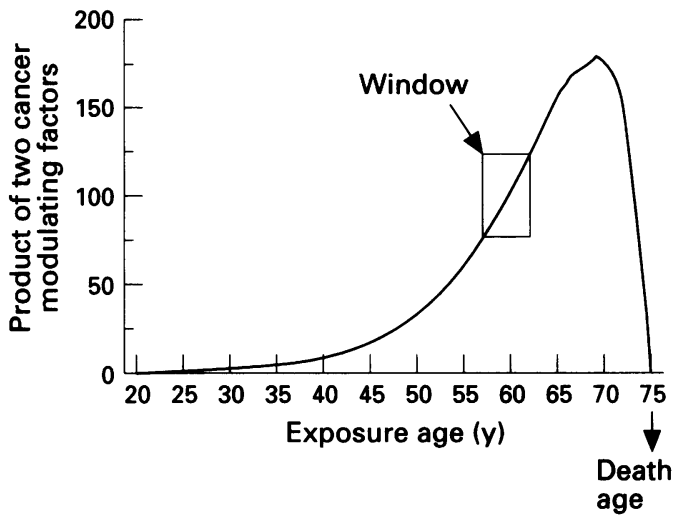

Figure 2 Window dose. Model IV estimate for cancer deaths at 75 years.
Table 7 Results of including five cohorts in four risk models

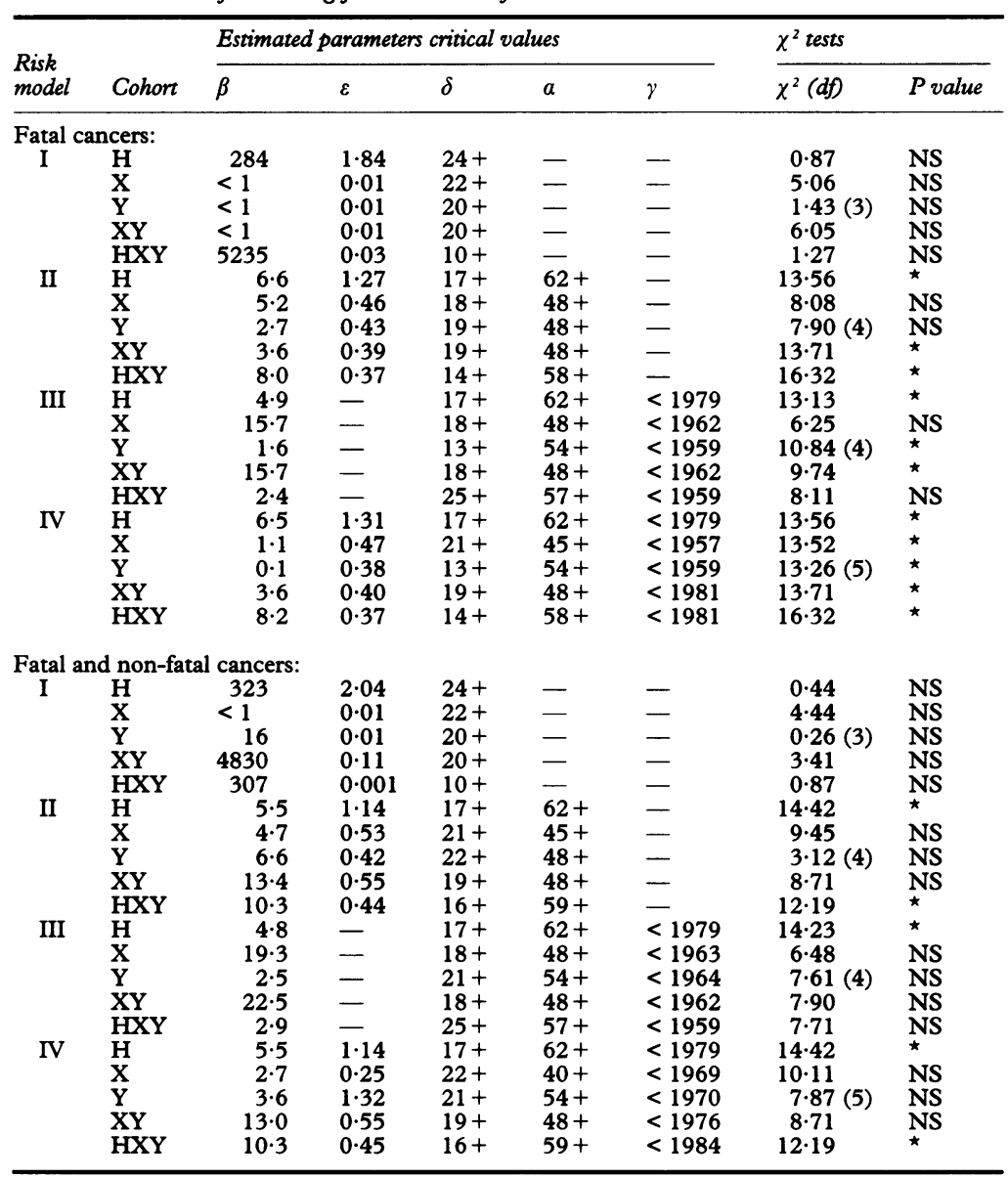

$\star P>0.05$

Table 8 Model IV: estimated numbers of high risk cases and radiogenic cancers

\begin{tabular}{|c|c|c|c|c|c|}
\hline \multirow[b]{2}{*}{ Series } & \multirow[b]{2}{*}{ Cohort ${ }^{\star}$} & \multicolumn{4}{|c|}{ Cancer cases } \\
\hline & & Totalt & Informativeł & High risk\$ & Radiogenic (\%) \\
\hline \multicolumn{6}{|l|}{ Fatal cancers: } \\
\hline & $\begin{array}{l}\mathrm{H} \\
\mathbf{X} \\
\mathbf{Y} \\
\mathbf{X Y} \\
\mathrm{HXY}\end{array}$ & $\begin{array}{r}1732 \\
401 \\
600 \\
1001 \\
2733\end{array}$ & $\begin{array}{r}1476 \cdot 7 \\
303.6 \\
461 \cdot 4 \\
765 \cdot 0 \\
2241 \cdot 7\end{array}$ & $\begin{array}{r}34 \\
47 \\
14 \\
88 \\
160\end{array}$ & $\begin{array}{l}14 \cdot 5(1 \cdot 0) \\
29 \cdot 2(9 \cdot 6) \\
10 \cdot 8(2 \cdot 3) \\
43.3(5 \cdot 7) \\
84.9(3 \cdot 8)\end{array}$ \\
\hline All cancers: & $\begin{array}{l}\mathrm{H} \\
\mathrm{HXY}\end{array}$ & $\begin{array}{l}1907 \\
2976\end{array}$ & $\begin{array}{l}1618 \cdot 5 \\
2436 \cdot 8\end{array}$ & $\begin{array}{r}42 \\
119\end{array}$ & $\begin{array}{l}18 \cdot 1(1 \cdot 1) \\
57 \cdot 1(2 \cdot 3)\end{array}$ \\
\hline
\end{tabular}

$\star$ Only cohorts with significant $\chi^{2}$ for model IV are included (table 7 ); †see table 1 ; $\ddagger$ cancer cases remaining after risk set matching; cases whose window doses equalled or exceeded the lowest from cohort H, 97 from cohort $\mathrm{X}$, and 59 from cohort $\mathrm{Y}$ ) (tables 10 and 11); festimates of the number of extra radiogenic cancers and the proportion of informative cases.
$(\mathrm{Z} / \beta)^{\varepsilon}$. The full set of five parameters for this model $(\beta$ and $\varepsilon$ as well as $a, \gamma$, and $\delta$ ) were estimated by the general method for cohort studies (as described by Breslow and Day ${ }^{13}$ ), with as controlling factors (for determining risk sets) all those listed in table 3.

By the gradual addition of extra parameters to a base model it was also possible to keep track of each effect, and thus be in a position to explore any problems created by non-uniform standards of dosimetry, after identifying suitable models (see $\chi^{2}$ in table 7). For example, the best fitting model IV was used to obtain risk estimates for different cohorts (tables 8-11) before testing for differences between pooled and unpooled data (table 12). Finally, since the 1991 analysis of Hanford doses had left an impression of much better dosimetry standards after than before $1960,{ }^{15}$ certain unexplained differences between the 1981 and 1993 analyses of Hanford data were also explored (tables 13 to 15 ).

\section{Results}

RISK MODEL SELECTION AND RESULTS

With the simplest of the four risk models (model I made no allowance for possible effects of age at exposure) there were no significant $\chi^{2} \mathrm{~s}$ in table 5 . With the remaining models (each with $10 \chi^{2}$ s) there were more significant results for the two cohorts containing Hanford workers ( $\mathrm{H}$ and HXY) than for the other cohorts, and more for fatal cancers than for all cancers. Only model IV had significant $\chi^{2}$ s for all five sets of fatal cancers, and only the three cohorts with more than a thousand fatal cancers $(\mathrm{H}, \mathrm{XY}$, and $\mathrm{HXY}$ ) had critical values for year of exposure that allowed each year of exposure to contribute to the window doses for these cases.

Within the model IV windows created by the estimated critical values of $\delta$ and $a$, the doubling doses for $\mathrm{H}$ and HXY were 6.5 and $8.2 \mathrm{mSv}$ (fatal cancers) or 5.5 and $10.3 \mathrm{mSv}$ (all cancers). For these cancer effective doses the age at exposure constraints were 58 and 62 years, and the cancer latency (lag period) constants were 14 and 17 years. For other cohorts with X10 workers ( $\mathrm{X}$ and $\mathrm{XY}$ ) the doubling doses were usually much lower $(1 \cdot 1$ and $3.6 \mathrm{mSv}$ for fatal cancers, or 2.7 and 13.0 $\mathrm{mSv}$ for all cancers) and there were also wider windows. Thus, the age at exposure constraints were 40 or 48 years and the lag period constraints were 19 or 21 years.

The $\chi^{2} \mathrm{~s}$ in table 7 were actually "improvements to twice the $\log$-likelihood relative to the null hypothesis of no radiation effect" (appendix). In relation to model IV, for the seven analyses that had significant $\chi^{2}$ s, the number of cancers with measurable window doses (see the high risk cases in table 8) ranged from 160 for HXY to 14 for Y. For cohort $\mathrm{H}$ the number of high risk cases was higher for all cancers (42) than for fatal cancers only (34), but for the fully pooled data (HXY) the number was lower for all cancers (119) than for fatal cancers (160). The proportion of high risk cases was higher for X10 
Table 9 Model IV: observed and expected numbers of fatal and non-fatal cancers for eight window doses and five cohorts

\begin{tabular}{|c|c|c|c|c|c|c|c|c|c|c|c|c|c|c|c|}
\hline \multirow{2}{*}{$\begin{array}{l}\text { Window } \\
\text { Doses } \\
m S v \dagger\end{array}$} & \multicolumn{3}{|c|}{ Cohort $H$} & \multicolumn{3}{|c|}{ Cohort $X$} & \multicolumn{3}{|c|}{ Cohort $Y$} & \multicolumn{3}{|c|}{ Cohort $X Y$} & \multicolumn{3}{|c|}{ Cohort $H X Y$} \\
\hline & Obs & $\operatorname{Exp}$ & $t$ value & $O b s$ & $\operatorname{Exp}$ & $t$ value & Obs & $\operatorname{Exp}$ & $t$ value & $O b s$ & Exp & $t$ value & Obs & $\operatorname{Exp}$ & $t$ value \\
\hline $\begin{array}{r}0.0 \\
0.1 \\
0.3 \\
1.0 \\
3.0 \\
10.0 \\
30.0 \\
100.0\end{array}$ & $\begin{array}{r}1865 \\
1 \\
8 \\
8 \\
13 \\
10 \\
2 \\
0\end{array}$ & $\begin{array}{r}1865.8 \\
2.56 \\
11.79 \\
11.33 \\
10.84 \\
4.03 \\
0.60 \\
0.00\end{array}$ & $\begin{array}{r}-0.22 \\
-1.08 \\
-1.40 \\
-1.34 \\
+0.97 \\
+3.91 \\
+1.86 \\
0.00\end{array}$ & $\begin{array}{r}347 \\
3 \\
12 \\
20 \\
24 \\
18 \\
2 \\
4\end{array}$ & $\begin{array}{r}358 \cdot 2 \\
2 \cdot 89 \\
11 \cdot 66 \\
17 \cdot 82 \\
21 \cdot 23 \\
12 \cdot 58 \\
4 \cdot 30 \\
1 \cdot 34\end{array}$ & $\begin{array}{l}-2.78 \\
+0.09 \\
+0.12 \\
+0.70 \\
+0.81 \\
+1.92 \\
-1.26 \\
+2.61\end{array}$ & $\begin{array}{r}630 \\
0 \\
2 \\
3 \\
1 \\
2 \\
1 \\
0\end{array}$ & $\begin{array}{c}632 \cdot 0 \\
0 \cdot 22 \\
2 \cdot 72 \\
2 \cdot 14 \\
1 \cdot 31 \\
0 \cdot 42 \\
0 \cdot 15 \\
0.00\end{array}$ & $\begin{array}{r}-1.16 \\
-0.49 \\
-0.64 \\
+0.75 \\
-0.32 \\
+2.62 \\
+2.29 \\
0.00\end{array}$ & $\begin{array}{r}947 \\
1 \\
17 \\
33 \\
23 \\
12 \\
8 \\
1\end{array}$ & $\begin{array}{r}984 \cdot 3 \\
2 \cdot 81 \\
15 \cdot 89 \\
30 \cdot 18 \\
20 \cdot 34 \\
10 \cdot 59 \\
4 \cdot 35 \\
0.56\end{array}$ & $\begin{array}{l}-2.09 \\
-1.17 \\
+0.34 \\
+0.75 \\
+0.76 \\
+0.53 \\
+2.00 \\
+0.64\end{array}$ & $\begin{array}{r}2927 \\
2 \\
11 \\
10 \\
14 \\
10 \\
2 \\
0\end{array}$ & $\begin{array}{r}2928 \cdot 1 \\
3.14 \\
13.66 \\
14.58 \\
11.83 \\
4.09 \\
0.60 \\
0.00\end{array}$ & $\begin{array}{r}-0.27 \\
-0.72 \\
-0.91 \\
-1.64 \\
+0.92 \\
+3.83 \\
+1.86 \\
0.00\end{array}$ \\
\hline $\begin{array}{l}\text { Total } \\
\text { Dose wei } \\
\text { Rank we }\end{array}$ & ted $t$ & $\begin{array}{l}907 \\
\text { lue } \\
\text { alue }\end{array}$ & $\begin{array}{l}3 \cdot 94^{\star} \\
2 \cdot 31^{\star}\end{array}$ & & 30 & $\begin{array}{l}2 \cdot 40^{x} \\
3 \cdot 15^{x}\end{array}$ & & 39 & $\begin{array}{l}3 \cdot 21 \\
2 \cdot 17\end{array}$ & & 69 & $\begin{array}{l}2 \cdot 20^{x} \\
2 \cdot 85^{x}\end{array}$ & \multicolumn{2}{|r|}{2976} & $\begin{array}{l}3 \cdot 86^{\star \star \star} \\
2 \cdot 05^{\star \star}\end{array}$ \\
\hline
\end{tabular}

${ }^{\star \star} \mathrm{P}<0.01 ;{ }^{\star \star \star} \mathrm{P}<0.001$. TThese are cancer effective doses. For the boundaries of the window doses see model IV (fatal and non-fatal cancers) (table 7 ).

(15.5\%) than Hanford $(2 \cdot 3 \%)$ despite the fact that the average dose was higher for Hanford than X10 (table 4). For numbers of radiogenic cancers there were estimates that ranged from 84.9 for $\mathrm{HXY}$ to 10.8 for $\mathrm{Y}$, and these too were much higher for $\mathrm{X} 10(29 \cdot 2)$ than for Hanford (14.5).

The total number of high risk cases to feature in one or more of the seven model IV analyses was 346 , with 190 from Hanford, 97 from X10, and 59 from elsewhere (see footnote to table 8 ). It was eventually discovered that the two larger cohorts formed from pooled data (XY and HXY) were not on exactly the same footing as the other cohorts (see later), so it was not possible to obtain corresponding numbers of radiogenic cancers. There was, however, no mistaking the fact that the cohort with the highest average dose

Table 10 Model IV: age distributions of fatal and non-fatal cancers: main series and high risk cases

\begin{tabular}{|c|c|c|c|c|}
\hline \multirow{2}{*}{$\begin{array}{l}\text { Death } \\
\text { age }(y)\end{array}$} & \multicolumn{2}{|l|}{ Hanford } & \multicolumn{2}{|l|}{ Elsewhere } \\
\hline & All cancers & High risk cases ${ }^{*}$ & All cancers & High risk cases * \\
\hline $\begin{array}{c}<60 \\
60-64 \\
65-69 \\
70-74 \\
75-79 \\
80-84 \\
\geqslant 85 \\
\text { Total } \\
7:\end{array}$ & $\begin{array}{c}600(26) \\
324(13) \\
355(29) \\
289(36) \\
195(38) \\
106(22) \\
38(11) \\
1907(175)\end{array}$ & $\begin{array}{l}- \\
- \\
29 \\
84(11) \\
52(12) \\
25(7) \\
190(30)\end{array}$ & $\begin{array}{c}470(9) \\
197(17) \\
184(14) \\
129(15) \\
61(8) \\
25(3) \\
3(2) \\
1069(68)\end{array}$ & $\begin{array}{c}- \\
3(1) \\
38(1) \\
57(7) \\
38(3) \\
19(2) \\
1 \\
156(14)\end{array}$ \\
\hline $\begin{array}{l}\mathrm{n} \\
\%\end{array}$ & $\begin{array}{l}628(107) \\
32 \cdot 9(61 \cdot 1)\end{array}$ & $\begin{array}{l}190(30) \\
100 \cdot 0(100 \cdot 0)\end{array}$ & $\begin{array}{l}218(28) \\
20 \cdot 4(41 \cdot 2)\end{array}$ & $\begin{array}{l}115(12) \\
73.7(85 \cdot 7)\end{array}$ \\
\hline
\end{tabular}

( ) Non-fatal cancers; *see footnote to table 8.

Table 11 Diagnostic categories of the model IV high risk cases

\begin{tabular}{|c|c|c|c|c|c|}
\hline \multirow[b]{2}{*}{ Facilities } & \multirow[b]{2}{*}{$I C D-8$} & \multicolumn{2}{|c|}{ Fatal and non-fatal cancers } & \multicolumn{2}{|c|}{ Fatal cases only } \\
\hline & & $\underset{n}{A l l}$ cases & $\begin{array}{l}\text { High risk cases } \\
n(\%)\end{array}$ & $\underset{n}{A l l}$ cases & $\begin{array}{l}\text { High risk cases } \\
n(\%)\end{array}$ \\
\hline \multicolumn{6}{|l|}{ Hanford: } \\
\hline & $\begin{array}{l}140-149 \\
150-159 \\
160-163 \\
170-174 \\
180-189 \\
190-199 \\
200-209 \\
\text { Total }\end{array}$ & $\begin{array}{r}44 \\
502 \\
578 \\
109 \\
272 \\
202 \\
200 \\
1907\end{array}$ & $\begin{array}{c}2(4 \cdot 5) \\
45(9 \cdot 0) \\
61(10 \cdot 6) \\
6(5 \cdot 5) \\
42(15 \cdot 4) \\
17(8 \cdot 4) \\
17(8 \cdot 5) \\
190(10 \cdot 0)\end{array}$ & $\begin{array}{r}41 \\
461 \\
532 \\
106 \\
223 \\
187 \\
182 \\
1732\end{array}$ & $\begin{array}{c}1(2 \cdot 4) \\
39(8 \cdot 5) \\
52(9 \cdot 8) \\
6(5 \cdot 7) \\
33(14 \cdot 8) \\
14(7 \cdot 5) \\
14(7 \cdot 7) \\
160(9 \cdot 2)\end{array}$ \\
\hline Elsewhere: & $\begin{array}{l}140-149 \\
150-159 \\
160-163 \\
170-174 \\
180-189 \\
190-199 \\
200-209 \\
\text { Total }\end{array}$ & $\begin{array}{r}22 \\
250 \\
351 \\
49 \\
143 \\
115 \\
139 \\
1069\end{array}$ & $\begin{array}{r}2(9 \cdot 1) \\
46(18 \cdot 4) \\
39(11 \cdot 1) \\
3(6 \cdot 1) \\
34(23 \cdot 8) \\
17(14 \cdot 8) \\
15(10 \cdot 8) \\
156(14 \cdot 6)\end{array}$ & $\begin{array}{r}19 \\
240 \\
334 \\
49 \\
131 \\
106 \\
122 \\
1001\end{array}$ & $\begin{array}{r}2(10 \cdot 5) \\
42(17 \cdot 5) \\
36(10 \cdot 8) \\
3(6 \cdot 1) \\
29(22 \cdot 1) \\
17(16 \cdot 0) \\
13(10 \cdot 7) \\
142(14 \cdot 2)\end{array}$ \\
\hline
\end{tabular}

(H) had a smaller proportion of radiogenic cancers $(1 \cdot 0 \%)$ than either $\mathrm{X}(9.6 \%)$ or $\mathrm{Y}$ $(2 \cdot 3 \%)$.

Table 9 shows that further results of applying model IV to all fatal and non-fatal cancers where observed and expected numbers of cancer cases (assuming no effects of radiation) are given positions on an eight point scale of window doses. As well as showing the effects of a much less restricted age range for the window doses of $\mathrm{X}$ than $\mathrm{H}$ (table 7 ), this arrangement of the data shows that both for dose-weighted and rank-weighted $t$ values, there were significant values even for the smallest cohort (which also had the lowest average dose). These findings were clearly the result of there being a dose-related risk of cancer even when the average dose was less than $1 \mathrm{mSv}$ a year (table 4). Thus, for window doses equal to or greater than $3 \mathrm{mSv}$, the ratio of observed to expected cancer cases was actually higher for the cohort with the lowest average dose ( $Y$ cohort, with four cases observed and 1.9 expected) than for Hanford ( 25 observed and 15.5 expected) or X10 (48 observed and 39.5 expected).

Given the age at exposure constraints of model IV (and the relatively large numbers of Hanford workers who were born before 1900) it was inevitable that the high risk cases would be older than average, and that this tendency would affect Hanford more than elsewhere (table 10). Also shown in this table is the high proportion of non-fatal cancers and cancer deaths after 70 years of age for high risk cancers, and the fact that the cohort with the longest follow up period (Hanford) accounted for $84 \%$ of the cancer deaths after 80 years. This cohort included $72 \%$ of the non-fatal cancers, $70 \%$ of the births before 1900 , and $100 \%$ of the deaths after 1984 . But instead of the proportion of high risk cases being higher for Hanford than elsewhere, the reverse was true (Hanford $2.3 \%$ and elsewhere $8 \cdot 0 \%$ ).

Finally, at Hanford and elsewhere there was a preponderance of genitourinary cancers both among the high risk cases and among the non-fatal cancers (table 11). These biases were probably the result of prostate tumours having an exceptionally good prognosis, as in other (histological) respects there was remarkably little difference between the high risk cases and the other cancers. 
Table 12 Tests of differences between two sets of pooled data (XY and HXY) and two components of each pool

\begin{tabular}{|c|c|c|c|c|c|c|}
\hline Series & Model & \multicolumn{2}{|c|}{ Cohorts $\chi^{2}$ values $\dagger$} & $\%^{2}$ difference $(d f)$ & $\begin{array}{l}\text { Critical } \\
\text { difference }\end{array}$ & $\begin{array}{l}\text { Significant } \\
\text { non-homogeneity }\end{array}$ \\
\hline \multirow{5}{*}{$\begin{array}{l}\text { Non-Hanford: } \\
\text { Fatal cancers }\end{array}$} & & $X Y$ & $X+Y$ & \multicolumn{3}{|c|}{ Differences between $X Y$ and $X+Y$} \\
\hline & I & $6 \cdot 05$ & $5 \cdot 06+1 \cdot 43$ & $0.44(3)$ & $7 \cdot 82$ & NS \\
\hline & II & $13 \cdot 71$ & $8.08+7 \cdot 90$ & $2 \cdot 27(4)$ & $9 \cdot 49$ & NS \\
\hline & III & $9 \cdot 74$ & $6 \cdot 25+10 \cdot 84$ & $7 \cdot 35(4)$ & $9 \cdot 49$ & NS \\
\hline & IV & $13 \cdot 71$ & $13 \cdot 52+13 \cdot 26$ & $13.07(5)$ & $11 \cdot 07$ & $\star$ \\
\hline \multirow{4}{*}{ All cancers } & I & $3 \cdot 39$ & $4 \cdot 44+0 \cdot 26$ & $1.34(3)$ & $7 \cdot 82$ & NS \\
\hline & II & $8 \cdot 71$ & $9 \cdot 45+3 \cdot 12$ & $3 \cdot 86(4)$ & $9 \cdot 49$ & NS \\
\hline & III & $7 \cdot 90$ & $6 \cdot 48+7 \cdot 61$ & $6 \cdot 19(4)$ & $9 \cdot 49$ & NS \\
\hline & IV & $8 \cdot 71$ & $10 \cdot 11+7 \cdot 87$ & $9 \cdot 27(5)$ & $11 \cdot 07$ & NS \\
\hline \multirow{5}{*}{$\begin{array}{l}\text { Hanford and else } \\
\text { Fatal cancers }\end{array}$} & sewhere: & $H X Y$ & $H+X Y$ & \multicolumn{3}{|c|}{ Differences between $H X Y$ and $H+X Y$} \\
\hline & I & $1 \cdot 27$ & $0.87+6.05$ & $5 \cdot 65(3)$ & $7 \cdot 82$ & NS \\
\hline & II & $16 \cdot 32$ & $13 \cdot 56+13 \cdot 71$ & $10.95(4)$ & $9 \cdot 49$ & * \\
\hline & III & $8 \cdot 11$ & $13 \cdot 13+9 \cdot 74$ & $14 \cdot 76(4)$ & $9 \cdot 49$ & * \\
\hline & IV & $16 \cdot 32$ & $13 \cdot 56+13.71$ & $10.95(5)$ & 11.07 & NS \\
\hline \multirow[t]{4}{*}{ All cancers } & I & 0.87 & $0 \cdot 44+3 \cdot 41$ & $2.94(3)$ & $7 \cdot 82$ & NS \\
\hline & II & $12 \cdot 19$ & $14 \cdot 42+8 \cdot 71$ & $10 \cdot 84(4)$ & $9 \cdot 49$ & $\star$ \\
\hline & III & $7 \cdot 71$ & $14 \cdot 23+7 \cdot 90$ & $14 \cdot 42(4)$ & $9 \cdot 49$ & * \\
\hline & IV & $12 \cdot 19$ & $14 \cdot 42+8 \cdot 71$ & $10 \cdot 84(5)$ & $11 \cdot 07$ & NS \\
\hline
\end{tabular}

* $\mathrm{P}<0 \cdot 05 ;$ † see table 7 .

Table 13 Cohort H: comparisons between global and local maximums for the log likelihood function

\begin{tabular}{|c|c|c|c|c|c|c|c|c|c|}
\hline \multirow{2}{*}{$\begin{array}{l}\text { Maximum of } \\
\text { log likelihood } \\
\text { function }\end{array}$} & \multirow[b]{2}{*}{ Cases } & \multicolumn{5}{|c|}{ Estimated model IV parameter } & \multicolumn{2}{|c|}{ Estimated numbers } & \multirow[b]{2}{*}{$\varkappa^{2}$ Values $(5 d f)$} \\
\hline & & $\beta$ & $\varepsilon$ & $\delta$ & $\alpha$ & $\ddot{i}$ & $\begin{array}{l}E D C \\
\text { cases }\end{array}$ & $\begin{array}{l}\text { Radiogenic } \\
\text { cases }\end{array}$ & \\
\hline \multicolumn{10}{|l|}{ Global: } \\
\hline & $\begin{array}{l}\text { Fatal cancers } \\
\text { All cancers }\end{array}$ & $\begin{array}{l}6 \cdot 5 \\
5 \cdot 5\end{array}$ & $\begin{array}{l}1 \cdot 31 \\
1 \cdot 14\end{array}$ & $\begin{array}{l}17+ \\
17+\end{array}$ & $\begin{array}{l}62+ \\
62+\end{array}$ & $\begin{array}{l}<1979 \\
<1979\end{array}$ & $\begin{array}{l}34 \\
42\end{array}$ & $\begin{array}{l}14 \cdot 3 \\
18 \cdot 1\end{array}$ & $\begin{array}{l}13 \cdot 56 \\
14 \cdot 42\end{array}$ \\
\hline Local: & $\begin{array}{l}\text { Fatal cancers } \\
\text { All cancers }\end{array}$ & $\begin{array}{l}34 \\
93\end{array}$ & $\begin{array}{l}0.17 \\
0.02\end{array}$ & $\begin{array}{l}8+ \\
8+\end{array}$ & $\begin{array}{l}50+ \\
50+\end{array}$ & $\begin{array}{l}<1956 \\
<1956\end{array}$ & $\begin{array}{l}255 \\
317\end{array}$ & $\begin{array}{r}89 \cdot 4 \\
154 \cdot 2\end{array}$ & $\begin{array}{l}12 \cdot 73 \\
14 \cdot 91\end{array}$ \\
\hline
\end{tabular}

EFFECTS OF POOLING DATA FROM DIFFERENT SITES

The method of identifying cancer deaths (originally devised by Mancuso et al ${ }^{1}$ ), was exactly the same for each cohort. It is often assumed that all sites controlled by the United States Nuclear Regulatory Commission (NRC) have uniform methods of dose estimation and monitoring programmes. Earlier work had shown that in these respects there

Table 14 Cohort H: comparisons between global and local maximums for model IV dose trends

\begin{tabular}{|c|c|c|c|c|c|c|}
\hline \multirow{2}{*}{$\begin{array}{l}\text { Model IV } \\
\text { window doses } \\
m S v\end{array}$} & \multicolumn{3}{|c|}{ Global maximum } & \multicolumn{3}{|c|}{ Local maximum } \\
\hline & $O b s$ & $\operatorname{Exp}$ & $t$ Value & $O b s$ & $\operatorname{Exp}$ & $t$ Value \\
\hline $0 \cdot 0$ & 1865 & $1865 \cdot 8$ & $-0 \cdot 22$ & 1580 & $1610 \cdot 2$ & $-3 \cdot 90$ \\
\hline $0 \cdot 1$ & 1 & 2.56 & -1.08 & 9 & $6 \cdot 69$ & +0.97 \\
\hline 0.3 & 8 & $11 \cdot 79$ & -1.40 & 71 & $62 \cdot 07$ & $+1 \cdot 41$ \\
\hline $1 \cdot 0$ & 8 & $11 \cdot 33$ & $-1 \cdot 34$ & 87 & $84 \cdot 08$ & +0.41 \\
\hline $3 \cdot 0$ & 13 & $10 \cdot 84$ & +0.97 & 107 & $97 \cdot 88$ & $+2 \cdot 14$ \\
\hline $10 \cdot 0$ & 10 & $4 \cdot 03$ & +3.91 & 34 & $30 \cdot 63$ & +0.75 \\
\hline $30 \cdot 0$ & 2 & 0.60 & $+1 \cdot 86$ & 18 & $15 \cdot 03$ & +0.89 \\
\hline $100 \cdot 0$ & 0 & 0.00 & 0.00 & 1 & 0.47 & +0.81 \\
\hline
\end{tabular}

$t$ Values dose weighted $=3.94^{\star \star \star} ; 1 \cdot 78$ NS rank weighted $=3 \cdot 46^{\star \star \star} ; 2 \cdot 31^{\star \star}$.

Table 15 High risk cases in cohort H: comparisons between global and local maximums

\begin{tabular}{llccc}
\hline ICD-8 & Global only & Global and local & Local only & Total \\
\hline $140-149$ & & 2 & 9 & 11 \\
$150-159^{\star}$ & 13 & $32(7)$ & $69(10)$ & $114(17)$ \\
$160-163^{\star}$ & $25(2)$ & $38(8)$ & $63(16)$ & $126(26)$ \\
$170-174^{\star}$ & 2 & 3 & 3 & 8 \\
$180-189$ & 13 & $98(8)$ & $37(13)$ & $78(21)$ \\
$190-199$ & $8(1)$ & $13(4)$ & $12(1)$ & $29(3)$ \\
$200-209^{\star}$ & 4 & $125(29)$ & $207(42)$ & $397(74)$ \\
Total & $65(3)$ & $86(19)$ & $149(28)$ & $279(49)$ \\
* (A) cancers: $\dagger$ & $44(2)$ & $68 \cdot 8$ & $72 \cdot 0$ & $70 \cdot 3$ \\
n & $67 \cdot 7$ & & \\
\hline
\end{tabular}

${ }^{\star}(\mathrm{A})$ Cancers are those with code number ${ }^{\star}$; $\nmid$ see Kneale et al ${ }^{\dagger}$; ( ) non-fatal cancers. was ample scope for differences between different locations and different years. ${ }^{1415}$

With comparable standards of dose recording in each facility and each calendar year, the risk estimates would be the same for pooled and unpooled data. Furthermore, with any well fitting model, the sum of two separate log likelihoods would be equal to the single $\log$ likelihood for the combined data. Therefore, table 12 shows for each model; $(a)$ the $\chi^{2}$ s for two sets of pooled data (cohort $X Y$ and HXY), (b) the $\chi^{2}$ s for two components of these sets (either $\mathrm{X}$ and $\mathrm{Y}$, or $\mathrm{H}$ and $\mathrm{XY}$ ), (c) the differences between the $\chi^{2} \mathrm{~s}$ for matching sets of pooled and unpooled data, and $(d)$ the critical $\chi^{2}$ s needed to establish significant difference between the matching sets.

For model I none of the $\chi^{2}$ differences for pooled and unpooled data came anywhere near the critical difference. For the smaller of the two data sets $(\mathrm{X}+\mathrm{Y}$ and $\mathrm{XY})$ only model IV succeeded in establishing any significant differences between the pooled and unpooled data, but for the larger set, $(\mathrm{H}+\mathrm{XY}$ and $\mathrm{HXY}$ ) there was definite evidence of a difference with models II and III, and suggestive evidence with model IV.

DIFFERENCES BETWEEN THE 1981 AND 1993 ANALYSES OF HANFORD DATA

Certain unexplained differences between the 1981 and 1993 analyses of Hanford data were the original reason for introducing two of the model IV parameters ( $\varepsilon$ and $\gamma$ ). These parameters were needed as in the earlier analysis, definite evidence of a dose related effect for a large group of cancers (A) was accompanied by negative dose trend for the remaining 
cancers (B). Therefore, for all cancers there was no certain evidence of any cancer effect. Furthermore, for A cancers, there was definite evidence of non-linearity of dose response, with an exponent of dose response well below unity. Neither of these findings was confirmed in the 1993 analysis. Therefore, bearing in mind the possibility of much better recording of radiation doses after than before $1960,{ }^{15} \mathrm{a}$ systematic search of the whole parameter space was made to discover whether, as well as a global maximum of log likelihood, there was also a local maximum that had more in common with the 1981 than the 1993 analysis.

Before this search was made it was arguable that controlling for levels of internal monitoring on the first occasion, and controlling for socioeconomic status on the second occasion, was sufficient to account for the different findings of the 1981 and 1993 analyses. The search both showed a local maximum, and showed that even with the same controlling factors there would have been significant differences between the 1981 and 1993 analyses (table 13). Thus, with the local maximum, the critical values were 50 years (for age at exposure) and 1956 (for year of exposure) and with the global maximum the corresponding values were 62 years and 1979. Furthermore, the $\varepsilon$ values for the exponent of dose response were much lower with the local maximum $(0.17$ or 0.02$)$ than with the global maximum $(1 \cdot 31$ or $1 \cdot 14)$.

If the correct value of $\varepsilon$ were as low as $0 \cdot 2$ there would be both a sizable risk of cancer at the lowest dose level and little change with increasing dose. For example, with a window dose of $0.1 \mathrm{mSv}$, the relative risk would be 1.37 for fatal cancers and 1.87 for all cancers, and a thousand fold increase (to $100 \mathrm{mSv}$ ) would only increase the relative risk to 2.05 or $2 \cdot 22$. Therefore, the absurdly low values of $\varepsilon$ with the local maximum were probably the result of there being a time when failure to record the true doses of process workers at Hanford was producing falsely small differences between the highest and lowest annual doses. In line with this suggestion is the 1991 analysis of Hanford doses ${ }^{15}$ that showed that before 1960 there were several years when the average annual dose was barely a tenth of later averages.

\section{Discussion}

The results of the present analysis are difficult to reconcile either with the assumption that the cancer experiences of atomic bomb survivors are a reliable source of risk estimates for nuclear workers, or with the assumption that the pooled data of IARC will prove to be a satisfactory alternative to atomic bomb data. The atomic bomb data are unsatisfactory because relations between age at exposure and risk of cancer are manifestly different for survivors and workers, and the pooled data of IARC are unsatisfactory because even within one source of these data (United States) there is evidence of cohort heterogeneity.
A slow unfolding of the mortality experiences of atomic bomb survivors has repeatedly left statisticians with an impression that there were $(a)$ no late effects of the bombing apart from a few extra cancer deaths; $(b)$ no risk of cancer below a certain dose level, and (c) a smaller risk of cancer for people who were over 50 years old when exposed than for younger survivors. Therefore, observers of the Hanford controversy, who included the United States Committee on Biological Effects of Ionising Radiation (BEIR), have repeatedly sided with the rebuttals. If the experiences of atomic bomb survivors were a true guide to the risk of cancers of nuclear workers, however, the effects of including age at exposure among the parameters of a relative risk model would have been very different from the observed effects. Likewise, if there had been uniform standards of dosimetry in all nuclear sites under NRC control, neither the comparisons between pooled and unpooled data in table 12 nor the comparisons between the global and local maxima in the tables, would have shown any significant differences.

Some idea of the extent to which the model IV risk estimates differ from estimates based on atomic bomb survivors can be gleaned by comparing the BEIR $\mathrm{V}$ and model IV estimates. ${ }^{16}$ According to BEIR V, if 100000 people with an average life span of 65 years had a continuous lifetime dose of $1.0 \mathrm{mGy} / \mathrm{y}$ they would probably experience 990 extra cancer deaths. With no such exposures the expected number of cancer deaths would be 20100 . Therefore, on this basis the average doubling dose would be close to $(20100 / 990)$ $\times 65$ or $1320 \mathrm{mGy}$. For the largest of five cohorts (HXY) model IV had $8.2 \mathrm{mSv}$ as the doubling dose for fatal cancers, 58 years as the critical age at exposure, and 14 years as the critical lag period (table 7, fig 2). Therefore, by 66 years of age an annual dose of $1.0 \mathrm{mSv}$ would be equivalent to a window dose of $8.2 \mathrm{mSv}$, and the number of cancer deaths after 80 years would be twice the expected number. Nowadays, both in the United States and in Britain, cancer deaths after 80 years account for $25 \%$ of all fatal cancers. Therefore, according to model IV, the average doubling dose would be close to 8.2 $\times 100 / 25$ or $33 \mathrm{mSv}$.

These are necessarily rough comparisons, but they are a reminder that it is only after 50 years of age that the model IV estimates are much higher than the BEIR V estimates (fig 1). These comparisons are also a reminder that although Kneale et al are not alone in producing higher estimates of relative risk for nuclear workers than for atomic bomb survivors - similar findings have been reported by Wing et al in the United States ${ }^{17}$ and by Kendal et al in the United Kingdom ${ }^{18}$-no one else has used a risk model that allows for cancer modifying effects of age at exposure and year of exposure. Failure to make any allowance for effects of age at exposure is clearly the reason why both the Gilbert et al analysis of Hanford data, and the IARC analysis of data from the United States, 
Canada, and Britain, failed to find any evidence of extra radiogenic cancers. For recognition of the necessarily small risk of cancers from the strictly controlled doses of nuclear workers it may also be important to know where and when the doses were recorded, as the model IV analysis has shown that even with strong central control of the United States nuclear industry it was not possible to maintain uniform standards of dosimetry either at different sites or in the same site at different times.

The strain placed on any cohort analysis by a need to consider several cancer modulating factors is immense. Nevertheless, by making suitable additions to routine statistical procedures, it has been possible to obtain a much clearer impression of what is happening in nuclear sites, and what may be happening elsewhere as a result of there being both continuous and universal exposure to natural background radiation.

\section{Appendix}

Up to the point of formal derivation of the optimal test of the four relative risk models, the statistical procedures were identical to the standard methods of Breslow and Day. ${ }^{13}$ But when it came to practical application of these results for computation of plausible models with the currently available data, there were many unsolved problems. For example, with all the possible confounders in table 3 the number of risk sets ran into millions. It was also possible for the same person to reappear in several risk sets, and this redundancy made the number of controls in each risk set so large that direct methods of calculation were impossible. Furthermore, one alternative to the null hypothesis (of no cancer effects of the radiation exposures) was that the risk increases linearly with dose. Therefore the risk model was more complex in computation than the standard logistic model (especially when it came to the calculation of differential coefficients). Finally, one of the possible models for the effects of cancer latency was that all doses within a critical prelag period had no effect. This would make differential coefficients for variation of likelihood with critical interval formally non-existent (as lag was necessarily measured in whole years). So there was a need to consider methods of calculating the maximum of the likelihood function that did not depend upon estimation of differential coefficients. Standard statistical packages such as PECAN could not easily be modified to resolve these problems as the situation was one that required separate identification of the effects of four dose weighting factors. Hence the need for the following additions to a standard cohort analysis.

\section{COMPUTATIONAL DIFFICULTIES}

Number of risk sets

Table 3 shows the nuisance parameters, together with their ranges. Multiplying these ranges together (to obtain the total number of possible risk sets) produced a figure of 4293120 . This was much too large for computer storage. Only the risk sets with cancer deaths were actually informative ones, and in a table of all possible risk sets the informative sets were so sparse that they could be indexed by the hash technique of Knuth. ${ }^{19}$ This reduced the storage requirement to slightly more than twice the number of cancer cases $(<6000)$.

Large risk sets

The number of selections of $n_{\mathrm{s}}$ objects taken without replacement from $\mathrm{N}_{\mathrm{s}}$ objects is of the order of $\mathrm{N}_{\mathrm{s}}{ }^{\mathrm{n}} \mathrm{s}$, and can be very large even when $N_{s}$ and $n_{s}$ are moderate. This number determined the number of terms in the denominator sum of products for the contribution to the likelihood (L) of the risk sets (s), and sets containing more than 10 cancer cases and more than 100 cases and matched controls were quite common. Therefore, direct calculation of $\mathrm{L}$ by the Breslow and Day formula ${ }^{13}$ was often impossible. Furthermore, direct calculation would have required storage of too many calculated values of relative risk. An alternative was found by realising that as a symmetrical function of relative risk was involved, these risks could be calculated from power sums in much the same way as $\kappa$ statistics can be calculated from moments. ${ }^{20} \mathrm{~A}$ suitable formula was derived as follows:

Let $\mathrm{i}$ index the individuals in a risk set with $\mathrm{n}$ cases, with a total of $\mathrm{N}$ cases and matched controls; $R_{i}$ be the calculated relative risk of individual $i ; S_{p}$ be the sum of the powers ( $p$ ) of the $R_{-}$-that is,

$S_{p}=\sum_{i=1}^{N} R_{i}^{p}$ and $D_{p}$ be the sum of the products over all selections of $p$ taken without replacement from the total of $\mathrm{N}$, and only ordered selections taken into account.

Thus: $\mathrm{D}_{1}=\sum_{i} \mathrm{R}_{\mathrm{i}}, \mathrm{D}_{2}=\sum_{i<i} \mathrm{R}_{i} \mathrm{R}_{\mathrm{i}}, \mathrm{D}_{3}=\sum_{i<i<k} \sum_{\mathrm{i}} \mathrm{R}_{i} \mathrm{R}_{i} \mathrm{R}_{\mathrm{k}}$ etc.

Then by inspection $D_{1}=S_{1}, 2 D_{2}=S_{1}{ }^{2}-S_{2}$ etc, and the following recursive result can be verified by the principle of alternating exclusion and inclusion:

$\left.\mathrm{pD}_{\mathrm{p}}=\sum_{\mathrm{q}=1}^{\mathrm{p}}(-1)^{(\mathrm{q}+1}\right) \mathrm{D}_{\mathrm{p}-\mathrm{q}} \mathrm{S}_{\mathrm{q}}$ where $\mathrm{D}_{0}$ is defined as unity. This left $\mathrm{D}_{\mathrm{n}}$ as the required denominator.

Also important is the fact that this result only required storage of $n_{0}$ power sums $S$ for each risk set, where $n_{5}$ was the maximum number of cases in the risk set. This meant that, together with the efficient storage of risk sets provided by the hash table technique, the total computer storage was not excessive.

\section{Non-differential likelihoods}

In the formula for the risk set contribution to $\mathrm{L}$ the derivation of the denominator from power sums of relative risks for risk sets made it hard to find the differential coefficients of $\mathrm{L}$ with respect to the parameters $(a, \beta$, $\gamma, \delta$, and $\varepsilon$ ) even although $\mathrm{L}$ itself is easily calculated. This meant that variants of the Newton-Raphson algorithm could not be used to find the values of the parameters that maximise L. Instead, L was maximised by varying the parameters directly and a suitable algorithm was the simplex one of Nelder and Mead. ${ }^{21}$

Method of the resulting computer program

A first pass through the data initialised the hash table for storage of the power sums of the informative risk sets. Then $-2 x \ln (L)$ was calculated for each successive approximation to the minimising parameters, by a single pass through the data. For each member of each study cohort the following procedures were used: if he or she were a case then $-2 x \ln (R)$ was added to $-2 x \ln (L)$, where $R$ was the relative risk in the death year. As the same person might be a control in other informative risk sets; each employment year of the hash table was scanned to see which risk sets with potential death years were informative and, where necessary, appropriate additions were made to the power sums. At the end of these passes through the data a sequential pass was made through the hash table (to calculate the denominator of each informative risk set from corresponding power sums) before updating the value of $-2 x \ln (L)$ by any contribution from the denominators. Finally, as a minor improvement, a constant for each risk set (depending on $n_{s}$ and $N_{s}$ ) was added to $-2 x \ln (\mathrm{L})$ so that the contribution to $-2 x \ln (\mathrm{L})$ was zero when all the relative risks in a given risk set were equal to unity. In other words, the final value of $-2 x \ln (\mathrm{L})$ was the approximate $\chi^{2}$ referred to in the text.

1 Mancuso TF, Stewart AM, Kneale GW. Hanford I: radiation exposures of Hanford workers dying from cancer tion exposures of Hanford workers dying from

2 Stewart AM, Kneale GW. An overview of the Hanford controversy. Occupational medicine: start of the art reviews. troversy. Occupational medicine: stant of the art
Philadelphia: Hanley and Belfus 1991;6:641-63. 
3 Kneale GW, Mancuso TF, Stewart AM. Hanford radiation study III: a cohort study of the cancer risks from radiation to workers at Hanford (1944-1977 deaths) by the method of regression models in life-tables. $\mathrm{Br} f$ Ind Med 1981;16:156-66.

4 Stewart AM, Kneale GW. The Hanford data: issues of age at exposure and dose recording. The PSR Quarterly 1993;3:101-11.

5 Kneale GW, Stewart AM. Reanalysis of Hanford data: 1944-86 deaths. Am $\mathcal{F}$ Ind Med 1993;23:371-89.

6 Gilbert ES, Marks S. An analysis of the mortality of workers in a nuclear facility. Radiat Res 1979;79:122-48.

7 Gilbert ES, Petersen GR, Buchanan A. Mortality of workers at the Hanford site: 1945-1981. Health Phys 1989;56:11-25.

8 Gilbert ES, Fry S, Wiggs L, Voelz GL, Cragle DL, Petersen GR. Analyses of combined mortality data on workers at the Hanford site, Oak Ridge national laboratory, and Rocky Flats nuclear weapons plant. Radiat Res 1989;120:1-17.

9 Gilbert ES, Omohundro E, Buchanan JA, Holter NA. Mortality of workers at the Hanford site: 1945-1986. Mortality of workers at the
Health Phys 1993;64:577-90.

10 Kato H, Schull WJ. Studies of the mortality of A bomb survivors: 7. Mortality, 1950-1978: Part 1. Cancer Mortality. Radiat Res 1982;90:395-432.

11 Gilbert ES, Cragle DL, Wiggs LD. Updated analyses of combined mortality data for workers at the Hanford site, Oak Ridge national laboratory, and Rocky Flats weapons plant. Radiat Res 1993;136:408-21.

12 IARC Study Group on cancer risk among nuclear industry workers. Direct estimates of cancer mortality due to low doses of ionizing radiation: an international study. Lancet 1994;344:1039-43.

13 Breslow NE, Day NE. Statistical methods in cancer research. Vol I. The analysis of case-control studies. Vol II. The design and analysis of cohort studies. Lyon: 1980. (IARC Sci Publ No 32:186.)

14 Wing $S$, Shy CM, Wood $J$, Wolf S, Cragle DI, Tankersley W, et al. Job factors, radiation and cancer mortality at Oak Ridge national laboratory: follow-up mortality at Oak Ridge national laboratory:

15 Kneale GW, Sorahan TM, Stewart AM. Evidence of biased recording of radiation doses of Hanford workers. Am f Ind Med 1991;20:799-803.

16 Beir V. Health effects of exposure to low levels of ionizing radiation. Washington, DC: National Academy Press, 1990.

17 Wing S, Shy CM, Wood JL, Wolf S, Cragle DL, Frome EL. Mortality among workers at Oak Ridge national laboratory: evidence of radiation effects in follow up through 1984. ҰAMA 1991;265:1397-402.

18 Kendall GM, Muirhead CR, MacGibbon BH, O'Hagan JA, Conquest AJ, Goodill AA, et al. Mortality and occupational exposure to radiation: first analysis of the pational Registry for Radiation Workers. BMf 1992; 302:220-5.

19 Knuth DE. The art of computer programming, sorting and searching. Vol 3. London: Addison-Wesley 1975.

20 Kendall MG, Stuart A. The advanced theory of statistics. Vol 1. Distribution theory. London: Charles Griffin 1963.

21 Nelder JA, Mead R. A simplex method for function minimization. Computer fournal 1965;7:308-13.

\section{Rejected manuscripts}

From February 1994, authors whose submitted articles are rejected will be advised of the decision and one copy of the article, together with any reviewers' comments, will be returned to them. The fournal will destroy remaining copies of the article but correspondence and reviewers' comments will be kept. 